\title{
Mechanical performance of compressed earth block masonry using granitic residual soils
}

\author{
D.V. Oliveira, T.F. Miranda, L.F. Ramos, R.A. Silva, E. Soares \& D. Leitão \\ ISISE, University of Minho, Depart. Civil Engineering, Guimarães, Portugal
}

\begin{abstract}
Although earthen construction has been practiced for millennia, its advantages associated to current environmental concerns are giving new opportunities to earth as a modern building material. The paper presents and discusses the first results of an experimental campaign carried out at University of Minho on the characterization of masonry components made of stabilized compressed earth blocks, produced with granitic residual soils, typically from Northern Portugal, and considering both dry-stack and mortared joints. The use of mortar joints modifies significantly the mechanical behaviour of masonry, both in terms of stiffness and strength.
\end{abstract}

\section{INTRODUCTION}

Earth has been used as building material since immemorial times with such an intensity that architecture in many ancient cultures was closely linked to this material (Schroeder 2016). Although still popular in many developing countries (e.g. Asia, Africa and Latin America), earthen construction felt clearly into disuse during the last 50 years in most of the developed countries (e.g. Europe).

The advantages associated to the use of earth as building material (e.g. very low embodied energy, almost no waste production, good thermal and acoustic performances, good fire resistance and relatively low cost) make it a sustainable building material (Pacheco-Torgal et al. 2012.). Nowadays, important concerns related to $\mathrm{CO}_{2}$ emission and energy consumption in the construction industry are giving new opportunities to earthen construction worldwide.

A major obstacle to the use of earthen construction is that earthen materials are typically classified as non-standard ones. Additionally, the lack of proper standards supporting earthen construction in most developed countries creates obstacles to its use and dissemination. Within this framework, traditional earthen construction solutions have been successively subjected to improvement of both the earthen materials and the building techniques. Masonry built with compressed earth blocks (CEBs) is one of the most significant improvements in the earth construction technology. CEBs are manufactured in manual or hydraulic presses, where the moistened earth is compacted inside a mould to form a block, which is immediately demoulded and put to dry. Further details on the production of CEBs are provided in Silva et al. (2015).

This paper presents the first results of an experimental program on the mechanical behaviour of drystack and mortared masonry made of CEBs with physical correction with kaolin and chemical stabilisation with cement. CEBs were manufactured with granitic residual soil, typical from northern Portugal. The experimental campaign consisted on axial compression tests on blocks, prisms and wallets as well as diagonal compression tests on wallets.

\section{EXPERIMENTAL CAMPAIGN}

\subsection{Materials}

The main material used to manufacture the CEBs consisted in granitic residual soil quarried close to the University of Minho, Guimarães. The suitability of the soil for producing CEBs was first assessed by means of soil characterization in terms of particle size distribution (LNEC 1966), consistency limits (LNEC 1969) and standard Proctor (LNEC 1967).

The particle size distribution curve of the soil is presented in Figure 1, where it is compared with the envelope of soils recommended for producing CEBs, according to the Spanish standard UNE 41410 (AENOR 2008). As can be observed, the clay content of the soil $(8.6 \%)$ is below the recommended range, as this standard discards the use of soils with clay content below $10 \%$. A minimum percentage of clay is required to the soil in order to provide initial cohesion and adequate strength to the CEBs. The 
initial cohesion is a property essential to the production phase, since CEBs must be handled immediately after their compaction.

Furthermore, the testing of the consistency limits showed that the soil is non-plastic. This situation points out that the activity of the clay fraction is low, indicating that the CEBs produced with this soil may not present adequate initial cohesion.

With respect to the results of the standard Proctor, the maximum dry density of the soil is of about $1.75 \mathrm{~g} / \mathrm{cm}^{3}$ and the optimum water content is of about 15.9\%. According to Doat et al. (1991), the maximum dry density of the soil corresponds to a fairly poor result, which may mean that CEBs produced with this soil may not present adequate strength.

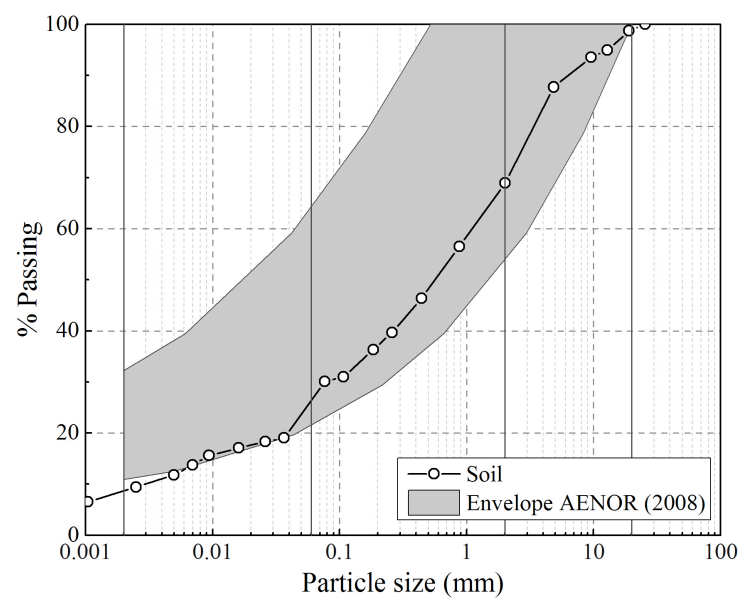

Figure 1. Particle size distribution of the soil and comparison with the envelope of soils for $\mathrm{CEB}$ production, recommended by UNE 41410 (AENOR 2008).

From the analysis of the characteristics of the soil, it was concluded that its use for producing CEBs required correction of the particle size distribution and chemical stabilisation. The correction of the particle size distribution consisted in the addition of 5\% (wt. of soil) of kaolin Mibal-A quarried and processed by Minas de Barqueiros, $S A$. The kaolin is mainly constituted by clay sized particles, which allow increasing the clay content of the soil to provide initial cohesion and higher strength. The percentage used corresponds to a minimum value to achieve this objective, since this material is the most expensive within the materials used to compose the CEBs. Chemical stabilisation was achieved by addition of $10 \%$ of cement CEM II/B-L $32.5 \mathrm{~N}$, provided by CIMPOR, to the soil (wt. of soil plus kaolin). Cement was preferred since it is expected to be the most efficient stabiliser, given that the soil presents low clay percentage and the clay fraction is mainly constituted by kaolin. Furthermore, a minimum amount of cement was required in order to provide adequate strength to the CEBs to allow their road transport on pallets to the laboratory facilities. A composition study for optimisation of the cement content was not carried out, but it should be noted that UNE 41410 (AENOR 2008) limits the cement stabilisation to a maximum of $15 \%$.

\subsection{Geometry and manufacturing of the blocks}

The geometry of the CEBs and the respective building system is presented in Figure 2. The design of the system resulted from HiLoTec Project, a previous partnership between the University of Minho and Mota-Engil, SA (Ramos et al. 2011). The geometry of the CEBs consists in a hollow block, which allows to build single- and double-leaf walls. The masonry built with these CEBs consists in a dry-stack interlocking system, relying on a docking mechanical connection (indentation) between CEBs. This system does not require the use of mortared joints, which makes the process simple and fast. Nevertheless the bedding effect of the mortar is not present, which is expected to result in the occurrence of tensile stresses in the CEBs.

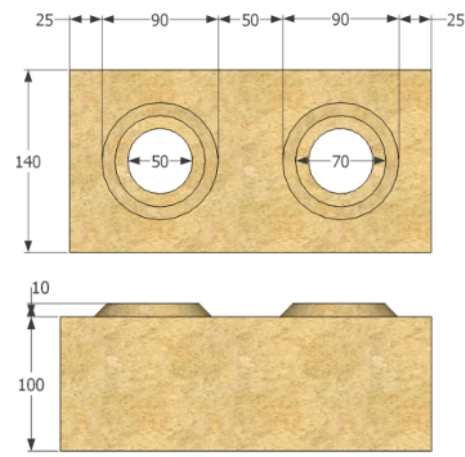

(a)

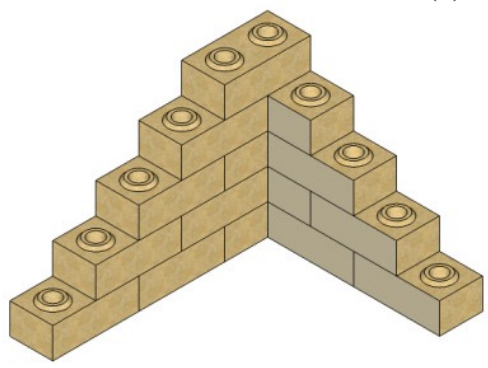

(b)

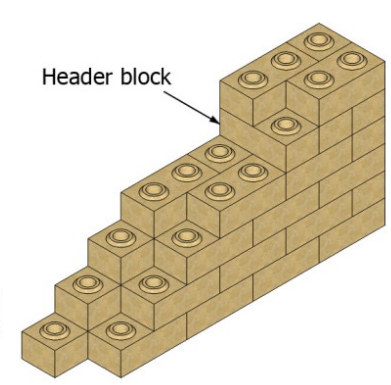

(c)
Figure 2. Dry-stack interlocking CEBs masonry system (Sturm et al. 2015): (a) dimensions of the block (in $\mathrm{mm}$ ); (b) singleleaf wall; (c) double leaf-wall.

In order to prepare the soil mixture to produce the CEBs, the soil was first left to dry at the air under a sheltered place with one open façade for a couple of days. Then the soil was sieved to remove the particles larger than $9 \mathrm{~mm}$. The mixture was manually prepared by, first, dry mixing the soil, kaolin and cement and, then, by mixing it with water. The addition of water was controlled by means of the ball drop test, according to NZS 4298 (Standards New Zealand 1998b). The mixture was then used to manufacture the CEBs, using a Terstaram ${ }^{\circledR}$ manual press. 
After compacting, the CEBs were putted on a pallet in five levels. The pallet was then wrapped in plastic film in order to promote the curing of the cement, since the film was able to retain the moisture of the mixture.

\subsection{Axial compression tests on blocks}

In order to assess the individual strength of the CEBs, three CEBs were tested under compression according to EN 772-1 (CEN 2011). The CEBs were tested under displacement control at a rate of about $4 \mu \mathrm{m} / \mathrm{s}$ and after a curing period of about 100 days (see Figure 3a).

\subsection{Axial compression tests on prisms}

The compression behaviour of the masonry built with the produced CEBs was tested on masonry prisms. The specimens were constituted by 5 stacked CEBs and were built using dry-stack or mortared joints. The mortar used in the last case was prepared with the soil used to produce the CEBs after removing the particles larger than $2 \mathrm{~mm}$ and smaller than $0.85 \mathrm{~mm}$. Cement CEM II/B-L $32.5 \mathrm{~N}$ was used as binder in the proportion $2: 9$ (cement : soil) and the $\mathrm{W} / \mathrm{S}$ ratio of the mortar was defined as 0.34 (Ribeiro 2015). The mechanical properties of the mortar were tested at an age of 28 days according to EN 1015-11 (CEN 1999a), resulting in average bending and compressive strengths of about $0.80 \mathrm{~N} / \mathrm{mm}^{2}$ and $2.2 \mathrm{~N} / \mathrm{mm}^{2}$, respectively. The idealised dimensions of the dry-stack prisms were of about $280 \times 500 \times 140 \mathrm{~mm}^{3}$ (width $\times$ height $\times$ thickness), while the mortared prisms included, additionally, bed joints with about $10 \mathrm{~mm}$ thick. In general, the slenderness of the prisms was of 5:1.4, meaning that the confinement effect introduced by the testing platens is practically insignificant. The testing of this type of arrangement, when compared with that of a full wall, has the advantage of being both simpler to install and of demanding a lower loading capacity. On the other hand, it should be noted that the prism specimens are not totally representative of the masonry pattern. The tests were carried out according to ASTM C1314-03b (ASTM 2003), but the load was applied under displacement control at a rate of about $4 \mu \mathrm{m} / \mathrm{s}$. The vertical displacements of each face were measured by means of 2 LVDTs placed between the $2^{\text {nd }}$ and $4^{\text {th }}$ blocks (see Figure $3 \mathrm{~b}$ ). Three prisms were tested for each type of joint, after a curing period of about 60 days for the CEBs and of about 30 day for the mortar.

\subsection{Axial compression tests on wallets}

Masonry wallets were also tested under compression, since these are more representative of the masonry than the prism specimens. Furthermore, the execution of tests on both types of specimens may lead to the establishment of relationships between them. The wallets were built on a reinforced concrete beam with dry-stack or mortared bed joints. The same mortar used to build the prisms was used to build the mortared wallets, where the thickness of the joints was of about $10 \mathrm{~mm}$. Each wallet was constituted by 7 courses with 2.5 CEBs and discontinuous cross joints. It should be noted that the idealised dimensions of the dry-stack wallets were of about $700 \times 700 \times 140 \mathrm{~mm}^{3}$ (width $\times$ height $\times$ thickness). Three wallets were tested for each type of joints, according to EN 1052-1 (CEN 1999b). The tests were carried out under displacement control with a rate of about $13 \mu \mathrm{m} / \mathrm{s}$. The vertical displacements on each face were measured by means of two LVDTs placed between the $2^{\text {nd }}$ and $6^{\text {th }}$ courses, while the horizontal displacements were measured by means of one LVDT placed in the intermediate course (see Figure $3 \mathrm{c})$.

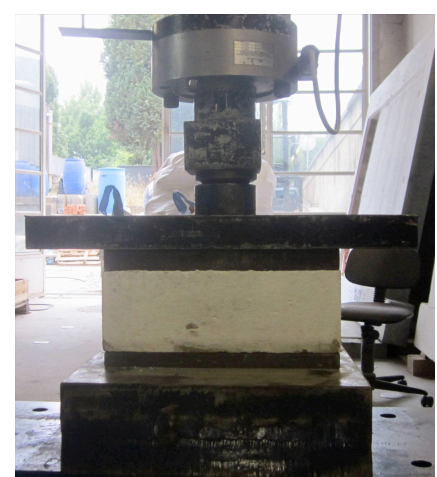

(a)

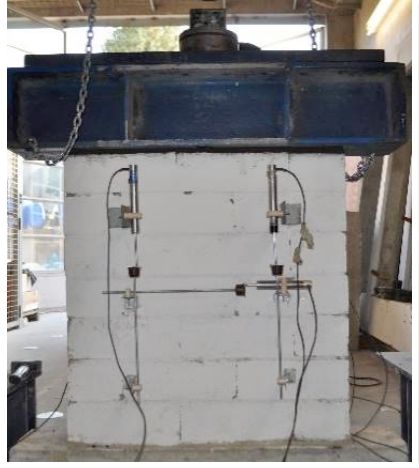

(c)

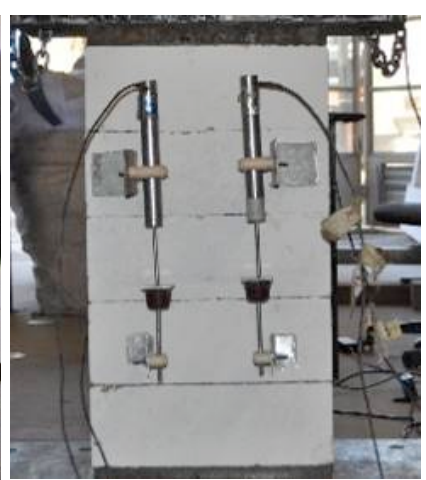

(b)

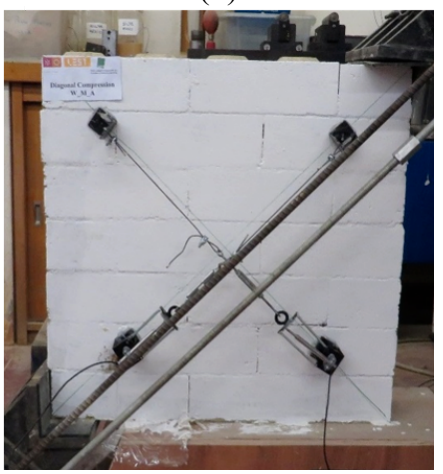

(d)
Figure 3. Setup of the tests performed in the experimental program: (a) compression test on CEBs; (b) compression tests on masonry prisms; (c) compression tests on masonry wallets; (d) diagonal compression tests on masonry wallets.

\subsection{Diagonal compression tests on wallets}

Wallets with the same geometry were tested under diagonal compression test according to ASTM E519 (2002). The standard suggests that, for performing compression tests diagonal walls are used with $1200 \times 1200 \mathrm{~mm}^{2}$ and with specimens rotated $45 \mathrm{de}-$ grees. In this case, for dry joint masonry wallets it was impossible to rotate the specimens at 45 degrees due to the absent of cohesion along the dry joints, 
being the tests carried out with the hydraulic actuator rotated (see Figure 3d). As far the overall geometry is concerned, it is expected that specimens with $700 \times 700 \times 140 \mathrm{~mm}^{3}$ (width $\times$ height $\times$ thickness) will not differ significant their response compared to the standard suggested geometry.

Since the test procedure was different from ASTM E519 (2002), a procedure already followed by other authors (Chriostrini et al. (2000); Brignola et al. (2008); Calderini (2009); Valluzzi et al. (2002); Corradi et al . (2010); Borri et al. (2011)) was used. The test setup was composed of two metallic wedges to apply the compression force, two steel rods with $10 \mathrm{~mm}$ diameter and respective connectors, a load cell, and a hydraulic actuator (see Figure $3 \mathrm{~d}$ ). The same testing configuration was used for mortared joints wallets.

Tests were carried out after 30 days of curing of the mortar under displacement control at a constant rate of $10 \mu \mathrm{m} / \mathrm{s}$. The response was recorded by 4 LVDT's placed in two diagonals (compression and tensile) on each side of the walls.

\section{RESULTS AND DISCUSSION}

\subsection{Axial compression tests on blocks}

The average compressive strength of the CEBs tested $\left(f_{c, b}\right)$ was of about $3.3 \mathrm{~N} / \mathrm{mm}^{2}$, where the minimum value obtained was of about $2.9 \mathrm{~N} / \mathrm{mm}^{2}$ and a coefficient of variation of about $11 \%$. The standard UNE 41410 (CEN 2008) defines three strength classes, namely BTC1, BTC3 and BTC5, where the normalized strength (percentile $5 \%$ ) should be equal or higher than $1.3 \mathrm{~N} / \mathrm{mm}^{2}, 3 \mathrm{~N} / \mathrm{mm}^{2}$ and $5 \mathrm{~N} / \mathrm{mm}^{2}$. The three tests performed do not provide a statistical representative sample to compute the percentile $5 \%$. Nevertheless, the minimum value obtained for the compressive strength after correction with the shape factor $(0.92)$ results into $2.67 \mathrm{~N} / \mathrm{mm}^{2}$. Thus the CEBs produced may be classified, at least, as BTC1. Furthermore, the CEBs achieved mechanical performance levels higher than those demanded by other regulating documents for CEB construction, namely NZS 4298 (Standards New Zealand 1998b) and HB 195 (Standards Australia 2002). This fact indicates that $\mathrm{CEBs}$ produced with granitic residual soils are capable of achieving adequate mechanical performance, providing that adequate correction measures are used (PSD correction and cement stabilisation).

\subsection{Axial compression tests on prisms}

The results of the axial compression tests on prisms are summarized in Table 1, in terms of average compressive strength $\left(f_{c, p}\right)$ and average Young's modulus $\left(E_{0, p}\right)$. The last parameter was computed between $5 \%$ and $30 \%$ of the compressive strength by linear fitting of the compression stress-axial strain curves, which are presented in Figure 4. Here, it should be noted that some curves are incomplete due to early detachment of the LVDTs from the blocks, caused by the occurrence of damage at the fixation points.

Table 1. Results of the axial compression tests on prisms (coefficient of variation inside brackets).

\begin{tabular}{cccc} 
Type of joint & $f_{c, p}\left(\mathrm{~N} / \mathrm{mm}^{2}\right)$ & $E_{0, p}\left(\mathrm{~N} / \mathrm{mm}^{2}\right)$ & $E_{0, p} / f_{c, b}$ \\
\hline Dry-stack & $2.1(25 \%)$ & $74(39 \%)$ & 22 \\
Mortared & $3.1(18 \%)$ & $538(24 \%)$ & 163 \\
\hline
\end{tabular}

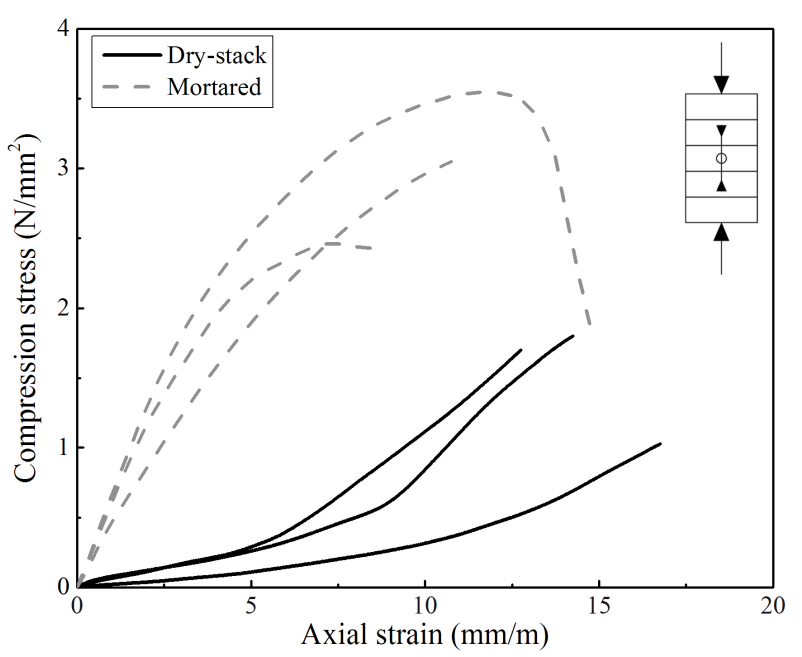

Figure 4. Stress - strain curves of the masonry prisms tested under axial compression.

The mortared prisms present the highest value of $f_{c, p}$, which is about $48 \%$ higher than that of the drystack prisms. Furthermore, the relationship between the compressive strength of the prisms and of the block is 0.6 and 0.9 for the dry-stack and mortared masonry, respectively. According to NZS 4297 (Standards New Zealand 1998a) the compressive strength of the masonry can be estimated as 0.5 times the compressive strength of the CEBs, which leads to a underestimation for both types of joints. This relationship seems to result in a safe estimation, although it should be noted that the behaviour of prisms may not be representative of the respective masonry system. The standard NZS 4297 (Standards New Zealand 1998a) also indicates that the Young's modulus of the masonry can be estimated as 300 times the compressive strength of the CEBs. This relationship leads to an overestimation of the Young's modulus of the masonry in both cases.

The lower value of the compressive strength of the dry-stack prisms results from the absence of the bedding effect of the mortar in the joints. The absence of this effect is reflected in the failure mode of the specimens, as depicted in Figure 5. In the case of the dry-stack masonry prisms, the absence of mortar originates concentration of tensile stresses that lead to the formation of discrete cracks in the blocks, 
which do not continue in the contiguous block. In the case of the mortared masonry prisms, failure seems to result from the formation of main cracks that extend from block to block.

The influence of the type of joint is also evident in the deformation behaviour of the masonry. The mortared masonry prisms are stiffer than those of dry-stack masonry, as depicted by the higher value of $E_{0, p}$ obtained for the mortared prisms (about 7 times higher) and by their stress - strain curves. In the case of the dry-stack prisms, these curves are characterised by an initial adjustment phase, which is related with accommodation between CEBs at the dry joints caused by the increasing load. In the case of the mortared prisms, the accommodation effect is not evident, resulting in deformations much lower than those of the mortared prisms for low values of stress.

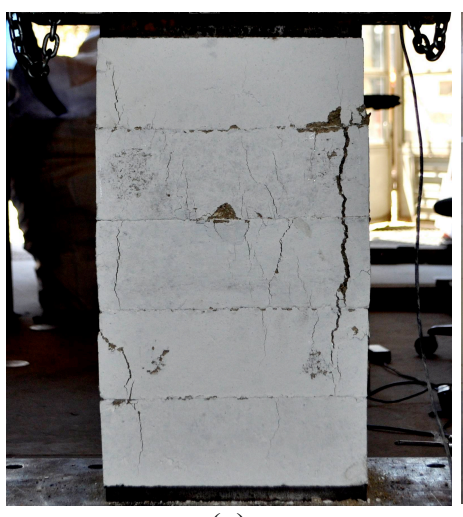

(a)

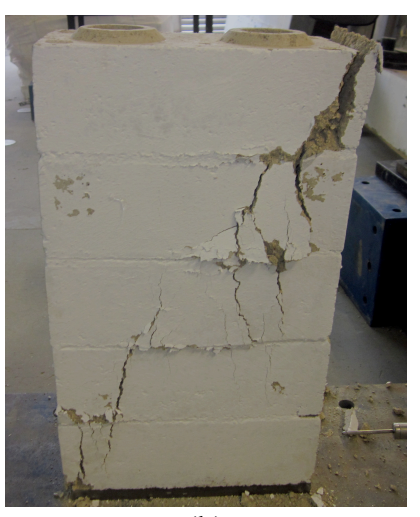

(b)
Figure 5. Failure mode of the prims: (a) dry-stack masonry; (b) mortared masonry.

\subsection{Axial compression tests on wallets}

The results of the axial compression tests on wallets are summarized in Table 2, in terms of average compressive strength $\left(f_{c, w}\right)$ and average Young's modulus $\left(E_{0, w}\right)$. The last parameter was computed between $5 \%$ and $30 \%$ of the compressive strength by linear fitting of the respective axial stress - strain curves, which are presented in Figure 6. This figure also presents the transversal stress - strain curves of the specimens

In general, the trends observed with respect to the results of prisms were observed with respect to the results of the wallets. The mortared wallets presented higher strength, higher stiffness and lower deformation (both in the axial and transversal directions) than those of the dry-stack wallets. Furthermore, the same reasons can be pointed out to explain these trends.

The relationship between the compressive strength of the wallets and of the block is 0.4 and 0.6 for the dry-stack and mortared masonry, respectively. In this case, the procedure of NZS 4297 (Standards New Zealand 1998a) to estimate the compres- sive strength of the masonry results into an overestimation in the case of the dry-stack masonry and in an underestimation in the case of the mortared masonry. Therefore, it should be highlighted that this relationship should be used carefully with respect to the type of masonry to be used. Furthermore, a decrease in strength of 0.70 times from the prisms to the wallets was observed for the dry-stack wallets, while that of the mortared wallets was of about 0.66 times. These results show that testing prisms may not provide reliable and representative results for both masonry systems, with respect to compressive strength.

Table 2. Results of the axial compression tests on wallets (coefficient of variation inside brackets).

\begin{tabular}{cccc}
\hline Type of joint & $f_{c, w}\left(\mathrm{~N} / \mathrm{mm}^{2}\right)$ & $E_{0, w}\left(\mathrm{~N} / \mathrm{mm}^{2}\right)$ & $E_{0, w} / f_{c, b}$ \\
\hline Dry-stack & $1.5(14 \%)$ & $60(13 \%)$ & 18 \\
Mortared & $2.0(17 \%)$ & $884(16 \%)$ & 268 \\
\hline
\end{tabular}

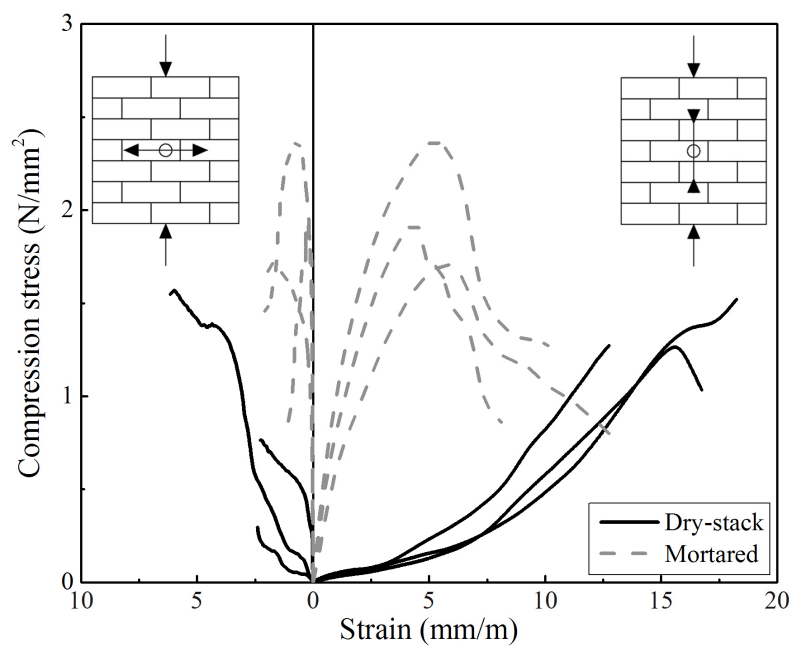

Figure 6. Compression stress - strain curves of the masonry wallets tested under compression.

With respect to the relationship for estimating the Young's modulus provided by NZS 4297 (Standards New Zealand 1998a), it leads to an overestimation in the case of the dry-stack wallets. In the case of the mortared masonry, it also provides an overestimation, still it seems to be a close estimation.

The failure mode of the wallets is depicted in Figure 7, where it is possible to observe that the failure of the dry-stack wallets is controlled by damage of the blocks occurring due to concentration of tensile stresses. On the other hand, the failure of the mortared wallets is related with the formation of a main crack with large extension.

Regarding the deformation behaviour of the wallets of both masonry systems, again the mortared masonry shows to be stiffer than the dry-stack masonry (about 15 times higher), which is a consequence of the accommodation effect aforementioned for the prisms. 


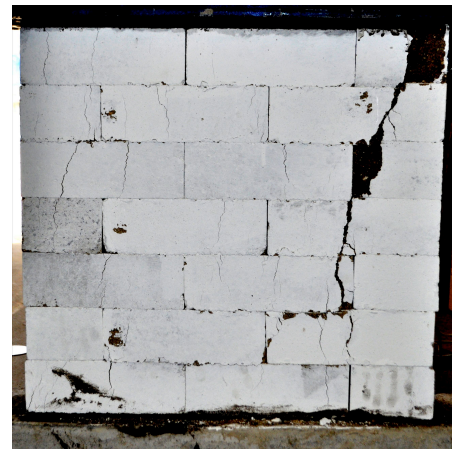

(a)

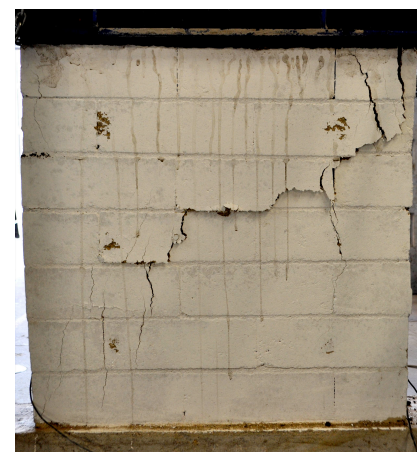

(b)
Figure 7. Failure mode of the wallets: (a) dry-stack masonry; (b) mortared masonry.

\subsection{Diagonal compression tests on wallets}

The results of the diagonal compression tests on wallets are presented in Table 3 , in terms of average shear strength $\left(S_{S}\right)$ on the basis of net area, and average modulus of rigidity or modulus of elasticity in shear $(G)$. The modulus of rigidity was computed in the elastic range by calculating the shear strain as the sum of both strains in compression and in tension. The diagonal stress - strain curves are presented in Figure 8.

A general remark between the dry-stack and the mortared joints wallets is the shear strength; the later have 4.8 times higher strength, which means that mortar joints play an important role in shear. The NZS 4297 (Standards New Zealand 1998a) stands that shear strength of earth walls for wind loading and for seismic load should equal $0.08 \mathrm{MPa}$, which is in the order of magnitude for dry-stack wallets and an underestimation value in the case of the mortared masonry.

Concerning the modulus of rigidity, a similar remark can be draw (ratio equal to 1:6.7). As expected, in case of dry-stack wallets the modulus of rigidity has lower values but the behaviour is more ductile, in opposition to the mortared wallets. No comments on this mechanical parameters are presented in the NZS 4297 (Standards New Zealand 1998a).

The failure modes of the wallets are presented Figure 9, where one can observe that for dry-stack wallets a major diagonal crack appears in the middle of the wall, splitting the specimen into two macro blocks. On the mortared wallets, less stress concentration are observed, since more than one significant shear crack were observed on the specimens. The first shear cracks appeared around $70 \%$ of the shear strength.

Table 3. Results of the diagonal compression tests on wallets (coefficient of variation inside brackets).

\begin{tabular}{cccc}
\hline Type of joint & $S_{s, w}\left(\mathrm{~N} / \mathrm{mm}^{2}\right)$ & $G_{0}\left(\mathrm{~N} / \mathrm{mm}^{2}\right)$ & $G_{0, w} / S_{s, w}$ \\
\hline Dry-stack & $0.05(21 \%)$ & $7.10(21 \%)$ & 142 \\
Mortared & $0.24(31 \%)$ & $228(10 \%)$ & 950 \\
\hline
\end{tabular}

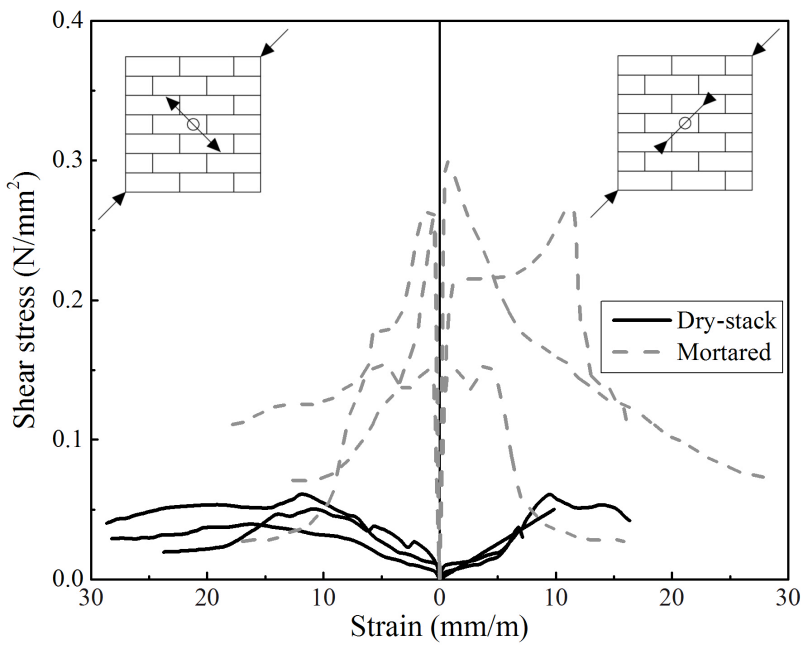

Figure 8. Diagonal stress - strain curves.

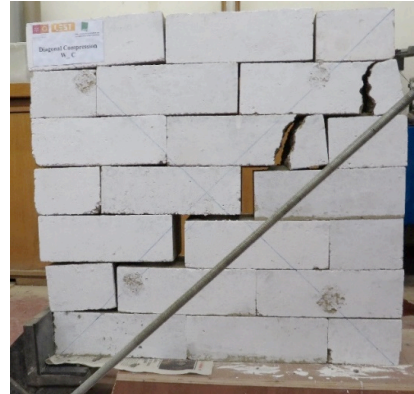

(a)

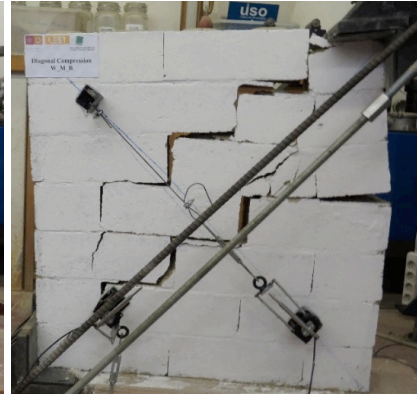

(b)
Figure 9. Failure mode of the wallets under diagonal compression tests: (a) dry-stack masonry; (b) mortared masonry.

\section{CONCLUDING REMARKS}

The granitic residual soil used in the experimental program was shown to be unsuitable due to its typical low clay percentage. The production of CEBs was made possible by applying correction measures, namely PSD correction with addition of 5\% kaolin and chemical stabilisation with $10 \%$ cement. The addition of kaolin allowed to obtain initial cohesion, while the cement stabilisation allowed to assure a suitable mechanical strength.

The experimental results evidence that the use of mortared joints is advantageous in order to obtain an improved mechanical behaviour of the masonry walls under compression and shear loading, despite the fact that building dry-stack masonry is cheaper and less time consuming. Nevertheless, it should be noted that optimizing the structural behaviour can be of major interest in regions with non-negligible seismic hazard.

The dry-stack masonry evidenced higher deformations due to the accommodation of blocks. This behaviour may have implications on the secondary elements of the walls. For instance, applied mortar coatings may fail (i.e. detach) as the wall is loaded 
(e.g. construction of new floors and overstressing due to a seismic event). Therefore, this type of deformation should be taken into account when building with dry-stack masonry.

\section{ACKNOWLEDGEMENTS}

Authors would like to express their gratitude to Manuel Carvalho and Ana Margarida Ribeiro for their valuable contribution in the experimental work. The grant SFRH/BPD/97082/2013 is acknowledged to FCT. The facilities used to produce and store the CEBs were kindly made available by Blonorte, Lda. This work was supported by FCT, within ISISE, project UID/ECI/04029/2013.

\section{REFERENCES}

AENOR 2008. UNE 41410: Compressed earth blocks for walls - Definitions, specifications and testing methods. Asociación Española de Normalización y Certificación, Spain. (in Spanish)

ASTM 2003. ASTM C1314-03b: Standard test method for compressive strength of masonry prisms. American Society for Testing and Materials, West Conshohocken, PA.

ASTM E519 2002. Standard test method for diagonal tension (shear) in masonry assemblages.

Borri, A., G. Castori, and M. Corradi. 2011. Shear behavior of masonry panels strengthened by high strength steel cords. Construction and Building Materials, Vol.25(2), pp. 494503.

Brignola, A., Frumento, S., Lagomarsino, S., Podestà, S. 2008. Identification of shear parameters of masonry panels through the in-situ diagonal compression test. International Journal of Architectural Heritage, Vol. 3(1), pp. 52-73.

CEN 1999a. EN-1015-11: Determination of flexural and compressive strength. European Committee for Standardization, Brussels.

CEN 1999b. EN 1052-1: Methods of test for masonry. Part 1: determination of compressive strength. European Committee for Standardization, Brussels.

CEN 2011. EN 772-1: Methods of test for masonry units. Part 1: Determination of compressive strength. European Committee for Standardization, Brussels.

Chiostrini, S.; Galano, L.; Vignoli, A. 2000. On the Determination of Ancient Masonry Walls Via Experimental Tests. Proceedings of the 12th World Conference on Earthquake Engineering, Auckland, New Zeland.

Corradi, M., Borri, A., Vignoli, A. 2003. Experimental study on the determination of strength of masonry walls, Journal of Construction and Building Materials, Vol.17(5), pp. 325-337.

Doat, P., Hays, A., Houben, H., Matuk, S. \& Vitoux ,F. 1991. Building with earth. The Mud Village Society, New Delhi.

LNEC 1966. LNEC E196: Soils: particle size distribution analysis. Especificação do Laboratório Nacional de Engenharia Civil, Lisbon, Portugal. (in portuguese)

LNEC 1967. LNEC E197: Soils: compaction test. Especificação do Laboratório Nacional de Engenharia Civil, Lisbon, Portugal. (in Portuguese)

LNEC 1969. NP 143: Soils: determination of the consistency limits. Laboratório Nacional de Engenharia Civil, Lisbon, Portugal. (in Portuguese)
Pacheco-Torgal F, Jalali S. 2012. Earth construction: lessons from the past for future eco-efficient construction. Construction and Building Materials, vol. 29, pp. 512-519.

Ramos, L.F., Mendonça, P., Camões, A., Sturm, T., Eires, R., Reis, P., Sousa, J. \& Vasconcelos, G. 2011. The partition walls of an integrated system of structural masonry made of CEBs. Seminário sobre Paredes Divisórias, Porto, Portugal. (in Portuguese)

Ribeiro, A. M. 2015. Innovative solutions to increase the comfort and seismic safety of CEB constructions. MSc Thesis, University of Minho, Portugal. (in Portuguese)

Schroeder, H. 2016, Sustainable building with earth, Springer.

Silva, R.A., Soares, E., Oliveira, D.V., Miranda, T., Cristelo, N., Leitão, D. 2015. Mechanical characterisation of drystack masonry made of CEBs stabilised with alkaline activation, Construction and Building Materials, Vol. 75, pp. 349-358.

Standards Australia 2002. HB 195: The Australian earth building handbook. Standards Australia, Sydney.

Standards New Zealand 1998a. NZS 4297: Engineering design of earth buildings. Standards New Zealand, Wellington.

Standards New Zealand 1998b. NZS 4298: Materials and workmanship for earth buildings. Standards New Zealand, Wellington.

Sturm, T., Ramos, L.F. \& Lourenço, P.B. 2014. Characterization of dry-stack interlocking compressed earth blocks. Materials and Structures, 48: 3059-3074.

Valluzzi, M. R., Tinazzi, D., and Modena, C. 2002. Shear behavior of masonry panels strengthened by FRP laminates, Construction and Building Materials, Vol.16(7), pp. 409416. 